\title{
Relative validity of a food frequency questionnaire among tin miners in China: 1992/93 and 1995/96 diet validation studies
}

\author{
MR Forman ${ }^{1, *}$, J Zhang ${ }^{2}$, L Nebeling ${ }^{3}$, S-X Yao ${ }^{2}$, MJ Slesinski ${ }^{4}$, Y-L Qiao ${ }^{5}$, S Ross $^{1,6}$,

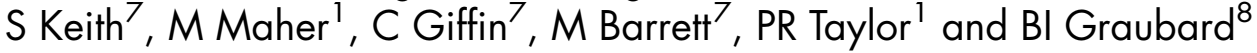 \\ ${ }^{1}$ Cancer Prevention Studies Branch, Division of Clinical Sciences, National Cancer Institute, Bethesda, \\ MD 20892-7326, USA: ${ }^{2}$ Labor Protection Institute, Yunnan Tin Mine Corporation, Gejiu, Yunnan, PR China: \\ ${ }^{3}$ Division of Cancer Control and Population Studies, National Cancer Institute, Bethesda, MD 20892-7326, USA: \\ ${ }^{4}$ WESTAT, 1850 Research Boulevard, Rockville, MD 20850-3129, USA: ${ }^{5}$ Department of Cancer Epidemiology, \\ Cancer Institute, Chinese Academy of Medical Sciences, Beijing 10002 1, PR China: ${ }^{6}$ Current address: Food and \\ Drug Administration, CFSAN, 200 C Street, Washington, DC 20204, USA: ' Information Management Sciences, \\ Silver Spring, MD 20904, USA: ${ }^{8}$ Biostatistics Branch, Division of Cancer Epidemiology and Genetics, National \\ Cancer Institute, Bethesda, MD 20892, USA
}

Submitted 24 July 1998: Accepted 21 January 1999

\begin{abstract}
Objective: Diet validation research was conducted to compare the respondents' reporting of dietary intake in a food frequency questionnaire (FFQ) with intake reported in food recalls. Because the population received annual salary increments that could modify food intake, diet validation studies (DVSs) were conducted during two time intervals.

Design: A 99-item FFQ was administered by an interviewer twice in a 1-year interval, and responses to each FFQ item were compared with 28 days of intervieweradministered food recalls that were collected in four 1-week intervals during each season of 1992/93. The second validation study in 1995/96 had a similar design to the earlier one.

Setting: A prospective cohort study of lung cancer among tin miners in China was initiated in 1992, with dietary and other risk factors updated annually.

Subjects: Among a cohort of high risk tin miners for lung cancer, two different samples ( $n=141$ in 1992/93, and $n=113$ in 1995/96) for each diet validation study were randomly selected from four mine units, that were representative of all worker units. Results: Miners reported a significantly higher average frequency of intake of foods in the food recalls than the FFQ, with few exceptions. Deattenuated Pearson correlation coefficients of the frequency of food intake between the FFQ and food recalls were in the range of -0.40 to 0.72 in both studies, with higher positive correlations for beverages and cereal staples than for animal protein sources, vegetables, fruits and legumes. The percentage of individuals with exact agreement in the extreme quartiles of intake in the food recalls and FFQ ranged from 0 to $100 \%$ in both studies.

Conclusions: Among Chinese miners, the range in correlations between the food recalls and the FFQ were due to: (i) market availability of foods during the food recall weeks compared to their annual reported intake in the FFQ; (ii) cultural perception of time; and (iii) differences in how the intake of mixed dishes and their multi-ingredient foods were reported in the recalls vs. the FFQ. The range in the percentage of agreement in the same quartiles and the changes in food intake over time may have implications for the analysis of the diet-disease relationship in this cohort.
\end{abstract}

Keywords
Diet validation
Food frequency
China
Across cultures in Asia, Africa and the Middle East, dietary assessment presents a challenge, because most foods are prepared as mixed dishes from small proportions of multiple ingredients and one large proportion of a staple such as rice ${ }^{1,2}$. Mixed dishes are prepared for a nuclear family or larger group of individuals, with meals perceived as a social event ${ }^{2}$. Utensils are primarily used in food preparation.
Chopsticks or a piece of pitta bread are common eating utensils, that cannot be standardized to measure individual intake. Seasonal variation in the food supply may challenge an individual's ability to estimate the frequency of intake of foods over the past year in a $\mathrm{FFQ}^{2}$. Local farms are the major source of food and therefore determine market availability. A small proportion of households may have refrigerators. The 
majority of the population may be illiterate or unable to record their intake in food records. Therefore, dietary assessment is dependent upon in-person interviews, that are costly, time-consuming and are conducted under logistically challenging conditions.

This paper focuses on diet validation research among tin miners residing in Yunnan Province, China. During the early 1990s, the lung cancer mortality rate was 487 per 100000 in the tin miners compared to an overall rate of 17.5 per 100000 in China $^{3}$. Lung cancer risk in the miners has been attributed to exposures to arsenic, radon and smoking ${ }^{4}$. Also, after adjustment for occupational exposures and smoking, dietary intakes of specific fruits, vegetables and animal protein sources were inversely related to the odds ratios of lung cancer $^{5,6}$. In the earlier diet-lung cancer case-control study, food taboos related to respiratory disease might have biased dietary recall among lung cancer patients 5 .

As part of a prospective cohort study of lung cancer among tin miners at the Yunnan Tin Corporation (YTC), a DVS was conducted to determine the validity of a FFQ that was administered at baseline in 1992 and again in 1993. The FFQ was compared to seven consecutive days of food recalls in each of the four seasons of the year, because food intake was expected to be seasonal and influence the accuracy of the FFQ. Because tin miners received annual salary increments that could modify food intake during the longer cohort study, a second DVS was conducted in 1995/96 similar to the $1992 / 93$ DVS.

The specific objectives of this paper are to: (i) describe the foods that are major contributors to food group intake and the seasonal differences in intake of these foods based on food recall data in the 1992/93 DVS and the 1995/96 DVS; (ii) compare and correlate the mean reported frequency of intake of major food contributors to food group intake from the 28 days of food recalls in the two DVSs with the corresponding FFQ in 1992, 1993 and 1995, respectively; and (iii) describe the extent to which individuals are correctly cross-classified by the DVS food recalls and FFQ.

\section{Materials and methods}

\section{Study population and samples in the 1992/93 and 1995/96 DVSs}

Participants in the YTC-National Cancer Institute (NCI) Lung Cancer Cohort Study were part of a screening cohort at high risk for lung cancer based on the following criteria: being either active or retired tin miners, who were aged $\geqslant 40$ years and had $\geqslant 10$ years of underground mining and/or smelting experience. About $95 \%$ of the high risk cohort were male. All consented to participate in the study ${ }^{4}$. The 1992/93 DVS sample $(n=202)$ was randomly selected from workers in four units: two mines; a mine and mineral dressing plant; and a smelter. These units reflected the overall configuration of worker units at the YTC. Sixty-one miners in the 1992/93 DVS were excluded from the analysis because seven were diagnosed with cancer or another chronic disease; and 54 had only completed 1-3 weeks of food recalls. Therefore the data analysis was based on $70 \%(n=141)$ of the original sample, all of whom had completed 4 weeks of food recalls. Mean age, height, weight, body mass index (BMI), education and percentage of current smokers at baseline did not differ among the 141 compared to those with 1-3 weeks of recalls (data not shown), but the 1992/93 DVS analytic sample $(n=141)$ was significantly younger and had a significantly higher income, educational level and percentage of active workers compared to the total cohort at baseline (Table 1).

The 1995 DVS sample $(n=128)$ was randomly selected from members of the high risk screening cohort who worked in the same four worker units as the 1992/93 DVS sample. Fifteen miners in the 1995 DVS were excluded from the analysis because they

Table 1 Demographic characteristics of the 1992/93 DVS, 1995/96 DVS and the total cohort at baseline

\begin{tabular}{|c|c|c|c|}
\hline Variable & $\begin{array}{c}1992 / 93 \text { DVS } \\
(n=141)\end{array}$ & $\begin{array}{c}1995 / 96 \text { DVS } \\
(n=113)\end{array}$ & $\begin{array}{l}\text { Baseline cohort } \\
\quad(n=6583)\end{array}$ \\
\hline $\begin{array}{l}\text { Age (years)* } \\
\text { Income }\left(\text { yuan month }{ }^{-1}\right)^{*} \\
\text { Education (years) } \\
\text { Weight }(\mathrm{kg})^{*} \\
\text { Height }(\mathrm{cm})^{*} \\
\text { BMI }\left(\mathrm{kg}^{2} \mathrm{~cm}^{-1}\right)^{*} \\
\text { Married }(\%) \\
\text { Active workers (\%) } \\
\text { Current smokers }(\%)\end{array}$ & $\begin{array}{l}54(9) \dagger \\
325(201) \dagger \\
5(5) \dagger \\
58(8) \\
162(5) \\
22(3) \\
95 \\
55 \dagger \\
83\end{array}$ & $\begin{array}{l}52(9) \ddagger \\
321(165) \\
5(4) \ddagger \\
58(9) \\
162(6) \\
22(3) \\
96 \\
58 \ddagger \\
75\end{array}$ & $\begin{aligned} & 55(8) \\
& 295(165) \\
& 4(4) \\
& 57(9) \S \\
& 162(6) \S \\
& 22(3) \S \\
& 94 \\
& 41 \\
& 78\end{aligned}$ \\
\hline $\begin{array}{l}{ }^{*} \text { Mean (SD). } \\
\dagger \text { Differences between the } 19 \\
\text { based on Student's } t \text {-test at } \\
\neq \text { Differences between the } 19 \\
\text { based on Student's } t \text {-test at } \\
\S n=6580 \text { because three mi }\end{array}$ & $\begin{array}{l}\text { VS sample a } \\
\text { de of } \leqslant 0.05 \text {. } \\
\text { VS sample a } \\
\text { de of } \leqslant 0.05 \text {. } \\
\text { are missing da }\end{array}$ & $\begin{array}{l}\text { seline cohort w } \\
\text { seline cohort w } \\
\text { baseline cohor }\end{array}$ & $\begin{array}{l}\text { tistically significant } \\
\text { tistically significant }\end{array}$ \\
\hline
\end{tabular}


had incomplete food recall data or were diagnosed with a chronic disease during the DVS. Compared to the baseline cohort, the 1995 DVS analytic sample ( $n=113$ ) was significantly younger, had a significantly higher educational level and a higher percentage of active workers at baseline (Table 1).

\section{Design}

In the first DVS, a 99-item culture-specific FFQ was administered by trained interviewers as part of the baseline screening of the high risk cohort of tin miners during the spring and summer of 1992. A follow-up FFQ was administered approximately 12 months later during the 1993 screening. Between the annual screens of the cohort when the FFQ was administered, the DVS sample completed 28 days of food recalls, that were interviewer-administered for seven consecutive days approximately 3 months apart. In the 1995/96 DVS, a FFQ was administered as part of the 1995 screen, and each season-specific food recall week occurred \pm 10 days of the same season-specific week in 1992/93.

The FFQ was designed to assess the frequency of intake of specific foods that were potentially related to lung cancer risk among Chinese tin miners ${ }^{5,6}$. Respondents to each FFQ had to recall the frequency of individual food or food group intake over the past year within five time intervals (i.e. daily, weekly, monthly, yearly or unknown) and estimated seasonal intake by recalling the number of months in which the food was eaten. The FFQ had several categories of food items including the following: staples/ cereals (five items); legumes (six items); fresh vegetables (27 items); pickled, salted or dried vegetables (five items); fruits (22 items); nuts and seeds (four items); foods from animal protein sources (16 items); beverages (seven items); and other foods (six items). In most sections of the FFQ, one or more blank spaces were provided for respondents to identify 'other foods' eaten in that food group. Also, respondents recalled the type of oil used in cooking; the frequency of intake of deep fried foods; the frequency of eating at home, in the mine cafeteria or elsewhere per week; use of vitamin supplements; and whether there was a refrigerator at home.

The food recall began with the respondent identifying whether the food intake during the previous day was 'typical or more or less than usual'. The interviewer then asked about intake of each food item in a mixed dish or eaten individually by time of day, preparation technique, gram amount and place of consumption. The interviewer used standardized serving utensils at the mine cafeterias, where the miners typically ate breakfast and lunch, and displayed tea containers, that the miners carried to work, to aid the respondent in estimation of amounts consumed. Food recalls were administered daily at home around the same time. No proxy interviews were permitted.
The same team of Chinese interviewers administered the DVS food recalls and FFQs over time. During a food recall week, the same interviewer administered the food recalls to the respondent. Food recalls were best suited for this population, because the majority had $<6$ years of education (Table 1 ) and most miners spent the day in underground facilities unable to complete food records. Supervisors reviewed food recalls daily, so that the interviewers could ask questions for clarification from the respondent during the interview on the following day. Foods were coded independently from the food recalls and the FFQ.

\section{Statistical analysis}

The analytic strategy involved four phases. In phase one, foods that were reported in the food recalls were classified into the food groupings of the FFQ (i.e. fruits, vegetables, legumes, animal protein sources, staple/ cereal foods and beverages). The total gram intake of each food was calculated from its intake over the 28 days of food recalls in each DVS. With these data, the percentage that each food contributed to the total food group intake over the year was calculated. Only foods that contributed $\geqslant 5 \%$ of the total gram intake of a food group were presented.

In phase two, the average daily gram intake of a food in each season was calculated by summing its gram intake over the food recall week and dividing by seven. Seasons were defined as: spring (March-May), summer (June-August), autumn (September-November) and winter (December-February). An analysis of variance model (ANOVA) was computed to compare seasonal differences in the average intake $\left(\mathrm{g} \mathrm{day}^{-1}\right)$ of specific foods. The ANOVA also included a separate intercept for each person to take into account repeated measurements (i.e. of multiple food recalls). The least square means $( \pm$ SE) of food intake by season were generated from the ANOVA using PROC GLM (SAS, Cary NC). All seasonal differences in food intakes were considered statistically significant at the $P$ value of $\leqslant 0.05$.

In phase three, 223 food codes from the food recalls were matched to one of the 99 items in the FFQ, with multiple food codes matched to single food questionnaire items. The purpose was to compare the reported frequency of intake of each food in the food recalls and FFQ of the 1992/93 and 1995/96 DVSs. Student's $t$-test was used to compare the mean daily frequency of intake of each food as reported in the food recalls with the reporting of its frequency in the FFQ, using a log transformation of the mean frequency to improve normality. The average daily frequency of intake of each food was calculated by counting each time that a respondent mentioned consumption of the food in the food recalls, summing the count and then dividing by 28 . For the FFQ, the frequency category for each food was converted to a daily frequency, after 
adjustment for seasonal intake as indicated by the number of months in the year that the food was eaten. The analysis was restricted to consumers of each food because of a high percentage of non-consumers of foods in specific food groups (Appendix 1).

In phase four, Pearson product-moment correlation coefficients were computed to examine the validity of the reported frequency of intake of foods, using logtransformed responses from the FFQ and from the food recalls in 1992/93 and 1995/96. Additional correlations were computed using weights to adjust for demographic differences in the DVS samples to the baseline cohort. Moreover, correlations were deattenuated by correcting for intra- and interindividual variability in intake, using formulas that were only available for Pearson correlations ${ }^{7-9}$. Finally, the reported frequency of intake of a food in the food recalls and its frequency in the FFQ were categorized into quartiles. The percentage of individuals who were classified in the same quartile of both dietary tools were calculated, with a focus on the percentage with exact agreement in the extreme quartiles of both dietary data sources.

\section{Results}

\section{Foods contributing to food group intake over time}

Based on the 1992/93 DVS food recalls, the foods contributing $5 \%$ or more to total fruit intake (presented in descending order of their per cent contribution) included: bananas, oranges and tangerines, apples, watermelon, peaches and pears (Table 2). By 1995/96, the average intake of watermelon $\left(\mathrm{g} \mathrm{day}^{-1}\right)$ was higher than the intake of bananas and replaced bananas as the major source of fruit intake. The remaining fruits had a lower per cent contribution than watermelon and bananas to total fruit intake. Mean daily intake of each fruit had increased over time, with the range in intake from $7-13 \mathrm{~g} \mathrm{day}^{-1}$ in 1992/93 to $11-22 \mathrm{~g} \mathrm{day}^{-1}$ in 1995/96.

In 1992/93, the foods contributing $5 \%$ or more to the total vegetable intake included: Chinese cabbage, dark green leafy vegetables, scallions plus leeks, potatoes, eggplant and lettuce root. By 1995/96, the average intake of Chinese cabbage, dark green leafy vegetables and potatoes had increased, whereas intake of lettuce root and eggplant had declined. Intake of these vegetables ranged from $11-44 \mathrm{~g} \mathrm{day}^{-1}$ in $1992 / 93$ to $8-50 \mathrm{~g} \mathrm{day}^{-1}$ in $1995 / 96$.

Fresh pork was the major source of animal protein, with eggs, beef, preserved pork, fish and chicken consumed less often. Between 1992/93 and 1995/96, consumption of preserved pork and beef had declined and fish and chicken intake had increased.

Among the foods contributing to legume intake in both DVSs, various preparations of bean curd, peanuts and bean sprouts were the major contributors. Mean
Table 2 Per cent contribution of each food to the total food group intake and average gram intake per day in the 1992/93 and 1995/96 DVSs

\begin{tabular}{|c|c|c|c|c|}
\hline \multirow[b]{2}{*}{ Food $^{*}$} & \multicolumn{2}{|c|}{ 1992/93 DVS } & \multicolumn{2}{|c|}{ 1995/96 DVS } \\
\hline & $\%$ & $\overline{\mathrm{x}} \pm \mathrm{SD}$ & $\%$ & $\bar{x} \pm S D$ \\
\hline \multicolumn{5}{|l|}{ Fruits } \\
\hline Banana & 28 & $13 \pm 11$ & 18 & $16 \pm 21$ \\
\hline Orange/tangerine & 19 & $12 \pm 14$ & 14 & $15 \pm 16$ \\
\hline Apple & 16 & $11 \pm 8$ & 14 & $15 \pm 15$ \\
\hline Watermelon & 8 & $9 \pm 7$ & 24 & $22 \pm 21$ \\
\hline Peach & 7 & $8 \pm 4$ & 10 & $15 \pm 13$ \\
\hline Pear & 7 & $7 \pm 5$ & 8 & $11 \pm 10$ \\
\hline \multicolumn{5}{|l|}{ Vegetables } \\
\hline Cabbage & 18 & $44 \pm 17$ & 18 & $50 \pm 28$ \\
\hline DGLV† & 7 & $18 \pm 11$ & 8 & $25 \pm 19$ \\
\hline Scallions/leeks & 6 & $16 \pm 6$ & 6 & $16 \pm 8$ \\
\hline Lettuce root & 5 & $13 \pm 9$ & $-\dagger$ & $9 \pm 10$ \\
\hline Potato & 5 & $12 \pm 9$ & 8 & $23 \pm 22$ \\
\hline Fresh eggplant & 5 & $11 \pm 5$ & $-\dagger$ & $8 \pm 6$ \\
\hline \multicolumn{5}{|l|}{ Animal protein sources } \\
\hline Fresh pork & 60 & $77 \pm 23$ & 55 & $70 \pm 28$ \\
\hline Eggs & 11 & $14 \pm 12$ & 13 & $17 \pm 16$ \\
\hline Beef & 7 & $11 \pm 10$ & $-\dagger$ & $9 \pm 11$ \\
\hline Preserved pork & 6 & $9 \pm 7$ & 5 & $8 \pm 7$ \\
\hline Fish & 5 & $10 \pm 8$ & 8 & $13 \pm 13$ \\
\hline Chicken & 5 & $9 \pm 7$ & 7 & $11 \pm 11$ \\
\hline \multicolumn{5}{|l|}{ Legumes } \\
\hline Fresh bean curd & 55 & $29 \pm 14$ & 34 & $26 \pm 19$ \\
\hline Peanut & 12 & $7 \pm 5$ & 17 & $14 \pm 13$ \\
\hline Strong smelling bean curd & 10 & $7 \pm 5$ & 15 & $13 \pm 10$ \\
\hline Bean sprouts & 9 & $6 \pm 4$ & 8 & $8 \pm 9$ \\
\hline \multicolumn{5}{|l|}{ Staples } \\
\hline Rice & 86 & $394 \pm 71$ & 84 & $412 \pm 129$ \\
\hline Noodles & 13 & $62 \pm 34$ & 16 & $77 \pm 50$ \\
\hline \multicolumn{5}{|l|}{ Beverages } \\
\hline Green tea & 80 & $877 \pm 489$ & 75 & $598 \pm 461$ \\
\hline Grain alcohol & 6 & $76 \pm 69$ & 6 & $90 \pm 109$ \\
\hline
\end{tabular}

DGLV, dark green leafy vegetables.

*Note that only foods that contribute to $\geqslant 5 \%$ of the total gram intake of a food group were presented because there were many more fruits, vegetables and legumes with minimal intake.

† These foods contributed to $\leqslant 5 \%$ of the total gram intake per day in 1995/ 96.

intake of legumes had a range from $6-29 \mathrm{~g} \mathrm{day}^{-1}$ in $1992 / 93$ to $8-26$ g day $^{-1}$ in $1995 / 96$. Rice, noodles, green tea and grain liquor remained the major food staples and beverages over time. Green tea consumption declined from 877 to $598 \mathrm{~g} \mathrm{day}^{-1}$ over the period. In contrast, the average intake of grain liquor increased from 76 to $90 \mathrm{~g} \mathrm{day}^{-1}$.

\section{Seasonal patterns in the intake of individual foods over time}

Seasonal differences in the average daily gram intake of specific fruits from the food recall data are presented in Fig. 1. (Note that the $y$ axis that identifies the gram intake per day for individual foods may vary.) Based on ANOVA modelling, bananas were consumed significantly more in spring, summer and autumn than in 



Fig. 1 Seasonal distribution of fruits (least square mean in day $^{-1}$ ): 1992/93 DVS vs. 1995/96 DVS. The 95\% upper limit as shown is derived from the SE of the least square mean, while the lower limit is not shown

winter in $1992 / 93$, but by $1995 / 96$, more consumption occurred in spring and autumn than in summer and winter. Watermelon was eaten significantly more in the autumn than in any other season in both DVSs. Apples and oranges/tangerines were eaten more in summer and winter than in spring and autumn, whereas peaches and pears were primarily consumed in the spring during both DVSs. 



Fig. 2 Seasonal distribution of vegetables (least square mean in day $^{-1}$ ): 1992/93 DVS vs. 1995/96 DVS. The 95\% upper limit as shown is derived from the SE of the least square mean, while the lower limit is not shown

Mean intake of specific vegetables significantly differed by season and their seasonal patterns of intake varied over time (Fig. 2). In both DVSs, consumption of dark green leafy vegetables peaked in winter and was also higher in summer than in autumn and spring. In 1992/93, Chinese cabbages were consumed more in winter than in the other seasons; by 1995/96, cabbages were eaten more in spring and winter than in summer and autumn. Intake of scallions and leeks was higher in summer and winter than in autumn and spring in 1992/ 93, however their intakes were higher in spring and autumn than in winter in 1995/96. The peak seasons 

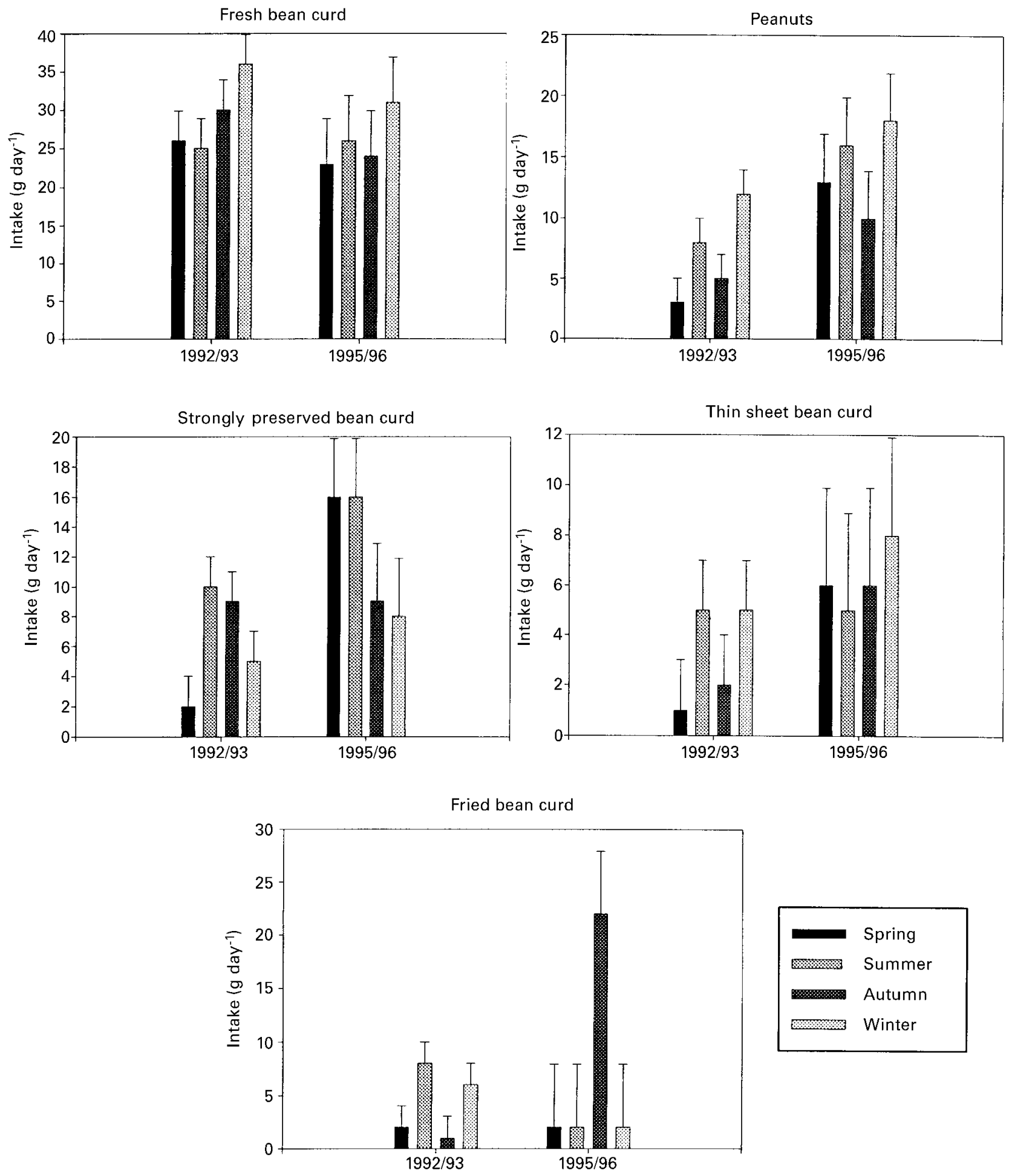

Fig. 3 Seasonal distribution of legumes (least square mean in g day $^{-1}$ ): 1992/93 DVS vs. 1995/96 DVS. The 95\% upper limit as shown is derived from the SE of the least square mean, while the lower limit is not shown

for consumption of eggplant occurred in spring and summer in 1992/93 and in spring and autumn in 1995/ 96. Intake of potatoes was higher in summer and autumn than in spring and winter in 1992/93, and intake in 1995/96 was higher in spring and autumn than in summer and winter.
Legume intake significantly varied by season over time (Fig. 3). Fresh bean curd was eaten more in winter than in spring and summer in 1992/93. By 1995/96, it was eaten more in winter than in spring and autumn. Peanuts were eaten more in winter than in any other season in 1992/93, but were eaten more in summer 

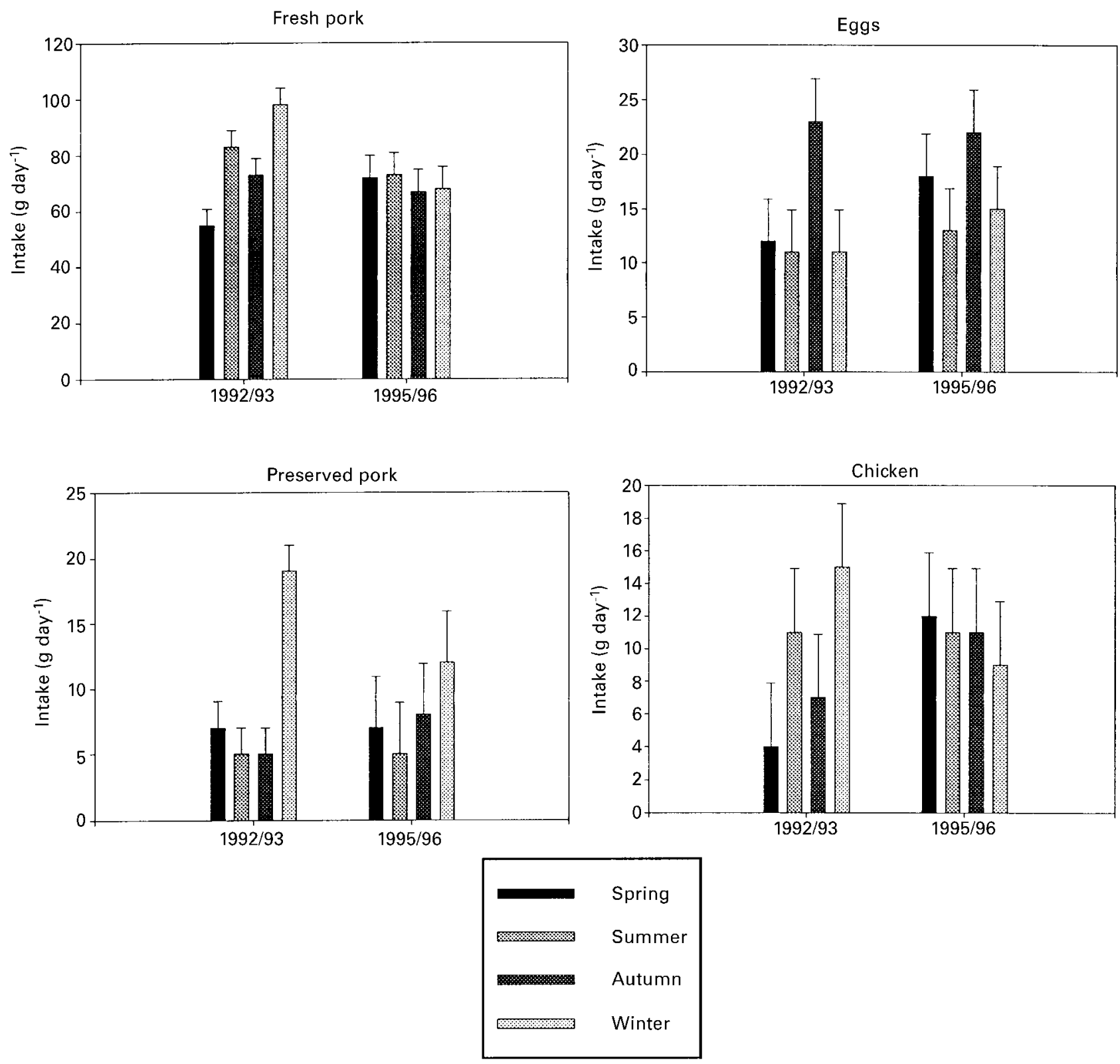

Fig. 4 Seasonal distribution of animal protein souces (least square mean in $\mathrm{g} \mathrm{day}^{-1}$ ): 1992/93 DVS vs. 1995/96 DVS. The $95 \%$ upper limit as shown is derived from the SE of the least square mean, while the lower limit is not shown

and winter than in the autumn by 1995/96. Strongly preserved bean curd was eaten more in the summer and autumn than the spring and winter in 1992/93; however, by $1995 / 96$, it was consumed more in the spring and summer than in the other seasons. Thin sheets of bean curd were eaten more in the summer and winter than in the spring and autumn in 1992/93, but seasonal differences were no longer significant in 1995/96. Fried bean curd was eaten more in the summer and winter than in the autumn and spring in 1992/93; while intake was higher in the autumn than in any other season in 1995/96.

Among animal protein sources, fresh pork was consumed more in summer, autumn and winter than in spring in 1992/93, but seasonal differences disappeared by 1995/96 (Fig. 4). Eggs were eaten more in the autumn than in any other season in both DVSs, and they were eaten more in the spring and autumn than in the summer and winter of 1995/96. Winter was the peak season for eating preserved pork. Also, chicken was consumed more in the winter and summer than in the spring and autumn in 1992/93, but seasonal differences disappeared by $1995 / 96$.

Miners drank green tea more in the spring than in the other seasons in 1992/93, but they drank it more in the autumn than in the other seasons in 1995/96 (Fig. 5). Miners drank grain liquor more in the summer and winter than in the spring and autumn of 1992/93. In 



Fig. 5 Seasonal distribution of tea and liquor (least square mean in g day $^{-1}$ ): $1992 / 93$ DVS vs. 1995/96 DVS. The 95\% upper limit as shown is derived from the SE of the least square mean, while the lower limit is not shown

1995/96, miners drank liquor more in the winter than in the other seasons and also more in the spring and summer than the autumn.

\section{Mean daily frequency of intake of foods across dietary tools over time}

Overall, the miners reported a significantly higher average daily frequency of intake of foods in the food recall data than in the FFQs in 1992/93 and in the 1995/ 96 DVS (Table 3). Specifically, they reported a higher frequency of intake of all vegetables, green tea, as well as most of the fruits, legumes, and the animal protein sources in the food recalls compared with their responses to the FFQs over time. Among the exceptions in the fruit group, the miners reported a similar frequency of intake of watermelon across the dietary tools in 1992/93 and a significantly higher average frequency of intake of bananas in the 1995 FFQ than the 1995/96 food recalls. Among the exceptions to the foods contributing to legume intake, miners reported a significantly higher frequency of intake of preserved bean curd in the 1992 and 1993 FFQs than in the 1992/93 food recall data. Among the animal protein sources, miners reported eating eggs more frequently in the FFQ than the food recalls over time.

Among the food staples, miners reported a significantly higher frequency of intake of rice in the 1993 FFQ than in the 1992/93 food recalls. Finally, miners reported drinking liquor significantly more frequently in the 1993 FFQ than the 1992/93 food recalls. An analysis of the median frequency of intake of each food revealed similar patterns to the means across dietary tools (data not shown).

\section{Correlation between the mean frequency of intake per day across dietary sources in the 1992/93 and the 1995/96 DVSs}

Deattenuated correlations tended to be higher than crude correlations, and therefore the results of the deattenuated ones are described. Deattenuated correlations for fruits ranged from -0.14 for oranges to 0.44 for bananas based on responses from the 1992/93 food recalls and the $1992 \mathrm{FFQ}$ (Table 4). The correlations for fruits from the same recall data and the $1993 \mathrm{FFQ}$ ranged from -0.15 for apples to 0.29 for bananas, with a dash indicating that the correlation for watermelon was unstable. The correlation for fruits based on the 1995/ 96 food recalls and the 1995 FFQ ranged from -0.09 for oranges to 0.30 for watermelon.

Deattenuated correlations for vegetables ranged from -0.39 for eggplant to 0.43 for dark green leafy vegetables using the 1992/93 food recall data and the 1992 FFQ. The correlations based on the same food recalls and the 1993 FFQ ranged from -0.04 for scallions/leeks and eggplant to 0.24 for cabbage. The correlations for vegetables based on the 1995/96 food recalls and the 1995 FFQ ranged from -0.13 for cabbage to 0.30 for eggplant.

Deattenuated correlations for various legumes based on the food recalls and the FFQ in 1992 ranged from 0.02 for bean sprouts to 0.49 for peanuts; whereas the correlations based on responses from the same food recalls and the 1993 FFQ ranged from -0.40 for preserved bean curd to 0.30 for peanuts. Finally, the correlations for legumes based on the 1995/96 food recalls and the 1995 FFQ ranged from -0.27 for preserved bean curd to 0.32 for peanuts.

Deattenuated correlations for animal protein sources ranged from 0.07 for chicken to 0.49 for fish based on the 1992/93 food recalls and the 1992 FFQ; while correlations ranged from -0.12 for preserved pork to 0.35 for fish using the same recall data and the 1993 FFQ. Correlations for animal protein sources based on the 1995/96 food recalls and the 1995 FFQ ranged 
Table 3 The frequency of intake per day ( $\bar{x} \pm$ SD) in the 1992/93 DVS food recalls, the 1992 and 1993 FFQs, the 1995/96 DVS food recalls and $1995 \mathrm{FFQ}$

\begin{tabular}{|c|c|c|c|c|c|}
\hline Food & 1992/93 DVS & $1992 \mathrm{FFQ}$ & 1993 FFQ & 1995/96 DVS & $1995 \mathrm{FFQ}$ \\
\hline \multicolumn{6}{|l|}{ Fruits } \\
\hline Bananas & $0.13 \pm 0.10$ & $0.10 \pm 0.14 \dagger$ & $0.11 \pm 0.12 \dagger$ & $0.16 \pm 0.18$ & $0.24 \pm 0.21 \dagger$ \\
\hline Apples & $0.11 \pm 0.07$ & $0.05 \pm 0.04 t$ & $0.07 \pm 0.09 \dagger$ & $0.13 \pm 0.14$ & $0.05 \pm 0.07 \dagger$ \\
\hline Watermelon & $0.04 \pm 0.02$ & $0.04 \pm 0.08^{*}$ & $0.04 \pm 0.04^{*}$ & $0.09 \pm 0.06$ & $0.06 \pm 0.05 \dagger$ \\
\hline Peaches & $0.08 \pm 0.04$ & $0.04 \pm 0.03 \dagger$ & $0.04 \pm 0.03 \dagger$ & $0.15 \pm 0.13$ & $0.06 \pm 0.05 \dagger$ \\
\hline Pears & $0.07 \pm 0.05$ & $0.05 \pm 0.05 \dagger$ & $0.07 \pm 0.08^{*}$ & $0.10 \pm 0.08$ & $0.06 \pm 0.08 \dagger$ \\
\hline Oranges/tangerines & $0.09 \pm 0.07$ & $0.06 \pm 0.07^{*}$ & $0.06 \pm 0.08^{*}$ & $0.15 \pm 0.14$ & $0.08 \pm 0.09 \dagger$ \\
\hline \multicolumn{6}{|l|}{ Vegetables } \\
\hline Potato & $0.20 \pm 0.11$ & $0.15 \pm 0.16 \dagger$ & $0.18 \pm 0.14 \dagger$ & $0.31 \pm 0.23$ & $0.20 \pm 0.12 \dagger$ \\
\hline Roots+ & $0.44 \pm 0.21$ & $0.07 \pm 0.09 \dagger$ & $0.08 \pm 0.07 \dagger$ & $0.24 \pm 0.15$ & $0.07 \pm 0.05 \dagger$ \\
\hline Scallions/leeks+ & $0.70 \pm 0.26$ & $0.55 \pm 0.28 \dagger$ & $0.59 \pm 0.31^{*}$ & $0.97 \pm 0.42$ & $0.78 \pm 0.33 \dagger$ \\
\hline Fresh eggplant & $0.25 \pm 0.11$ & $0.06 \pm 0.05 \dagger$ & $0.04 \pm 0.04 \dagger$ & $0.14 \pm 0.09$ & $0.07 \pm 0.04 \dagger$ \\
\hline Cabbage+ & $0.66 \pm 0.21$ & $0.07 \pm 0.08 \dagger$ & $0.11 \pm 0.15 \dagger$ & $0.60 \pm 0.28$ & $0.07 \pm 0.06 \dagger$ \\
\hline $\mathrm{DGLV}_{+}$ & $0.22 \pm 0.14$ & $0.19 \pm 0.18 \dagger$ & $0.18 \pm 0.17 \dagger$ & $0.26 \pm 0.16$ & $0.40 \pm 0.26 \dagger$ \\
\hline \multicolumn{6}{|l|}{ Legumes } \\
\hline Fresh bean curd & $0.45 \pm 0.19$ & $0.21 \pm 0.18 \dagger$ & $0.26 \pm 0.21 \dagger$ & $0.33 \pm 0.20$ & $0.33 \pm 0.20$ \\
\hline Preserved bean curd & $0.08 \pm 0.07$ & $0.11 \pm 0.16^{*}$ & $0.09 \pm 0.14 \dagger$ & $0.12 \pm 0.10$ & $0.06 \pm 0.07 \dagger$ \\
\hline Bean sprouts & $0.11 \pm 0.08$ & $0.09 \pm 0.09 \dagger$ & $0.11 \pm 0.10^{*}$ & $0.14 \pm 0.12$ & $0.15 \pm 0.17^{*}$ \\
\hline Peanuts & $0.21 \pm 0.14$ & $0.15 \pm 0.16 \dagger$ & $0.18 \pm 0.24 \dagger$ & $0.37 \pm 0.32$ & $0.26 \pm 0.22 \dagger$ \\
\hline \multicolumn{6}{|l|}{ Animal protein sources } \\
\hline Pork & $1.26 \pm 0.37$ & $0.55 \pm 0.35 \dagger$ & $0.58 \pm 0.37 \dagger$ & $1.39 \pm 0.50$ & $0.66 \pm 0.30 \dagger$ \\
\hline Eggs & $0.22 \pm 0.17$ & $0.23 \pm 0.24 \dagger$ & $0.29 \pm 0.28 \dagger$ & $0.28 \pm 0.23$ & $0.37 \pm 0.23^{*}$ \\
\hline Beef & $0.17 \pm 0.15$ & $0.07 \pm 0.10 \dagger$ & $0.07 \pm 0.08 \dagger$ & $0.17 \pm 0.23$ & $0.07 \pm 0.11 \dagger$ \\
\hline Preserved pork & $0.18 \pm 0.13$ & $0.06 \pm 0.12 \dagger$ & $0.09 \pm 0.15 \dagger$ & $0.18 \pm 0.15$ & $0.08 \pm 0.13 \dagger$ \\
\hline Fish & $0.15 \pm 0.12$ & $0.05 \pm 0.07 \dagger$ & $0.05 \pm 0.08 \dagger$ & $0.21 \pm 0.19$ & $0.08 \pm 0.11 \dagger$ \\
\hline Chicken & $0.11 \pm 0.08$ & $0.03 \pm 0.04 \dagger$ & $0.04 \pm 0.07 \dagger$ & $0.14 \pm 0.12$ & $0.04 \pm 0.04 \dagger$ \\
\hline \multicolumn{6}{|l|}{ Staples and beverages } \\
\hline Rice & $2.51 \pm 0.23$ & $2.63 \pm 0.49$ & $2.70 \pm 0.46 \dagger$ & $2.35 \pm 0.33$ & $2.48 \pm 0.50$ \\
\hline Noodles & $0.42 \pm 0.21$ & $0.45 \pm 0.31$ & $0.37 \pm 0.30$ & $0.46 \pm 0.27$ & $0.43 \pm 0.28$ \\
\hline Green tea & $1.77 \pm 0.64$ & $1.00 \pm 0.67 \dagger$ & $1.00 \pm 0.49 \dagger$ & $1.34 \pm 0.86$ & $0.93 \pm 0.35 \dagger$ \\
\hline Liquor & $0.66 \pm 0.57$ & $0.88 \pm 0.79$ & $1.11 \pm 0.83 \dagger$ & $0.73 \pm 0.68$ & $0.60 \pm 0.57$ \\
\hline
\end{tabular}

+ , more than one vegetable of the same group is included; DGLV, dark green leafy vegetables.

${ }^{*} P \leqslant 0.05$ based on Student's $t$-tests comparing the log-transformed mean daily frequency from the DVS food recalls vs. FFQ. $\dagger P \leqslant 0.01$.

from 0.18 for preserved pork to 0.43 for beef. Finally, deattenuated correlations for cereal staples and beverages ranged from 0.23 for rice to 0.70 for liquor based on the 1992/93 food recalls and the 1992 FFQ; while correlations ranged from 0.31 for green tea to 0.72 for liquor using the same recall data and the $1993 \mathrm{FFQ}$. The correlations for cereal staples and beverages ranged from 0.20 for noodles to 0.68 for liquor based on the $1995 / 96$ food recalls and the $1995 \mathrm{FFQ}$.

\section{Joint classification of individuals into the extreme quartiles of the DVS food recalls and FFQs}

The percentage of miners who were correctly classified in the highest quartile of the frequency of intake of a food in the 1992/93 food recalls and 1992 FFQ (i.e. per cent with exact agreement) were in the range from $11 \%$ for roots to $92 \%$ for green tea (Table 5). The percentage with exact agreement in the highest quartiles of the same food recalls and the 1993 FFQ were in the range from $16 \%$ for eggs to $97 \%$ for green tea; while the percentage with exact agreement in the highest quartiles of the 1995/96 food recalls and the 1995 FFQ were in the range from $0 \%$ for preserved bean curd to $100 \%$ for green tea. The percentages of miners classified in the lowest quartile of the frequency of intake of a food in the 1992/93 food recalls and the $1992 \mathrm{FFQ}$ were in the range from $17 \%$ for eggplant to $57 \%$ for liquor; while the percentage in the lowest quartile of intake in the same recalls and the 1993 FFQ ranged from 9\% for cabbage to $73 \%$ for liquor. Finally, the percentage of miners with exact agreement in the lowest quartile of the 1995/96 food recalls and the 1995 FFQ were in the range from $11 \%$ for noodles to $70 \%$ for liquor.

The frequency of consumption of tea and grain liquor (i.e. beverages) consistently had the highest percentage of agreement in the extreme quartiles over time. In contrast, the frequency of consumption of individual vegetables had the lowest percentages with exact agreement in the extreme quartiles of the food recalls and FFQ in the 1992/93 DVS. Fruit was not consumed frequently, and therefore an ' $x$ ' indicated that there were insufficient numbers of individuals to fill the $4 \times 4$ contingency table. In contrast, rice was 
Table 4 Pearson correlation coefficients (crude and deattenuated) between the 1992/93 DVS food recalls and the 1992 and 1993 FFQs and between the 1995/96 DVS food recalls and 1995 FFQ

\begin{tabular}{|c|c|c|c|c|c|c|c|c|}
\hline \multirow[b]{2}{*}{ Food } & \multicolumn{2}{|c|}{$n$} & \multicolumn{3}{|c|}{ Crude } & \multicolumn{3}{|c|}{ Deattenuated } \\
\hline & 1992 & 1995 & 1992 FFQ & $1993 \mathrm{FFQ}$ & $1995 \mathrm{FFQ}$ & $1992 \mathrm{FFQ}$ & 1993 FFQ & $1995 \mathrm{FFQ}$ \\
\hline \multicolumn{9}{|l|}{ Fruits } \\
\hline Bananas & 81 & 52 & $0.38 \dagger$ & $0.25^{\star}$ & 0.06 & $0.44 \dagger$ & $0.29^{\star *}$ & 0.07 \\
\hline Apples & 54 & 45 & 0.03 & -0.12 & 0.00 & 0.04 & -0.15 & 0.00 \\
\hline Watermelon & 32 & 51 & -0.08 & 0.21 & 0.20 & 0.33 & - & 0.30 \\
\hline Peaches & 33 & 30 & 0.33 & 0.02 & 0.09 & 0.49 & 0.04 & 0.11 \\
\hline Pears & 35 & 33 & 0.07 & 0.03 & 0.10 & 0.10 & 0.04 & 0.12 \\
\hline Oranges/tangerines & 59 & 44 & -0.11 & 0.01 & -0.08 & -0.14 & 0.01 & -0.09 \\
\hline \multicolumn{9}{|l|}{ Vegetables } \\
\hline Potato & 137 & 110 & $0.27^{\star \star}$ & 0.12 & 0.03 & 0.41 & $0.18^{*}$ & 0.04 \\
\hline Roots+ & 141 & 101 & 0.03 & -0.03 & 0.08 & 0.04 & -0.03 & 0.10 \\
\hline Scallions/leeks+ & 141 & 113 & 0.03 & -0.02 & 0.11 & 0.05 & -0.04 & 0.12 \\
\hline Fresh eggplant & 140 & 94 & -0.17 & $-0.19^{*}$ & 0.18 & -0.39 & -0.04 & 0.30 \\
\hline Cabbage & 141 & 112 & 0.16 & 0.04 & 0.03 & 0.20 & 0.24 & -0.13 \\
\hline DGLV+ & 127 & 107 & $0.29^{\star *}$ & 0.13 & -0.07 & $0.43^{\star \star}$ & 0.19 & -0.09 \\
\hline \multicolumn{9}{|l|}{ Legumes } \\
\hline Fresh bean curd & 141 & 111 & 0.11 & 0.13 & $0.26^{\star *}$ & 0.14 & 0.17 & $0.30^{* *}$ \\
\hline Preserved bean curd & 56 & 65 & 0.27 & -0.31 & -0.21 & 0.35 & $-0.40^{\star}$ & -0.27 \\
\hline Bean sprouts & 116 & 86 & 0.01 & 0.07 & -0.07 & 0.02 & 0.09 & -0.09 \\
\hline Peanuts & 131 & 103 & $0.39 \dagger$ & $0.24^{*}$ & $0.30^{* *}$ & $0.49 \dagger$ & $0.30^{* *}$ & $0.32^{* *}$ \\
\hline \multicolumn{9}{|l|}{ Animal protein sources } \\
\hline Pork & 141 & 112 & $0.21^{*}$ & 0.12 & $0.22^{*}$ & $0.27^{*}$ & 0.16 & $0.23^{*}$ \\
\hline Eggs & 139 & 107 & $0.23^{* \star}$ & $0.19^{*}$ & 0.32 & $0.28^{\star *}$ & $0.23^{*}$ & $0.35^{\star *}$ \\
\hline Beef & 109 & 64 & $0.34 †$ & $0.22^{*}$ & $0.41^{* *}$ & $0.39 \dagger$ & $0.25^{\star}$ & $0.43 \dagger$ \\
\hline Preserved pork & 123 & 86 & 0.08 & -0.09 & 0.15 & 0.11 & -0.12 & 0.18 \\
\hline Fish & 99 & 60 & $0.39 \dagger$ & $0.29^{*}$ & 0.18 & $0.49 \dagger$ & $0.35 \dagger$ & 0.20 \\
\hline Chicken & 101 & 86 & 0.05 & 0.00 & $0.32^{* *}$ & 0.07 & 0.00 & $0.39^{* *}$ \\
\hline \multicolumn{9}{|l|}{ Staples and beverages } \\
\hline Rice & 141 & 113 & 0.20 & $0.48 \dagger$ & $0.28^{* *}$ & $0.23^{\star}$ & $0.56 \dagger$ & $0.30^{* *}$ \\
\hline Noodles & 140 & 112 & $0.38 \dagger$ & $0.36 \dagger$ & 0.19 & $0.42 \dagger$ & $0.40 \dagger$ & $0.20^{*}$ \\
\hline Green tea & 141 & 106 & $0.28^{* \star}$ & $0.28^{* \star}$ & $0.37 \dagger$ & $0.32^{* *}$ & $0.31^{\star *}$ & $0.38 \dagger$ \\
\hline Liquor & 116 & 90 & $0.68 \dagger$ & $0.70 \dagger$ & $0.67 \dagger$ & $0.70 \dagger$ & $0.72 \dagger$ & $0.68 \dagger$ \\
\hline
\end{tabular}

+ , more than one vegetable of the same group is included; DGLV, dark green leafy vegetables.

* $P \leqslant 0.05$.

** $P \leqslant 0.01$.

$\dagger P=0.001$

eaten two to three times per day and its frequency could not be stratified into quartiles.

\section{Discussion}

The purpose of the 1992/93 DVS was to examine the validity of a FFQ compared with 28 days of food recalls among tin miners who were at high risk of lung cancer. The analyses involved the examination of the foods contributing to food group intake and their seasonal pattern of intake, as well as the correlation between, and ranking of, miners by their responses to the food recalls and FFQ. Because the tin miners received salary increments annually, the 1995/96 DVS was conducted for comparison with the earlier DVS.

Contributors to food group intake, their seasonal patterns of intake and changes over time

A variety of fruits, with different seasonal peaks, contributed to fruit intake. The major contributors to vegetable intake were white and dark green vegetables, with peak seasons of intake clustering in either the autumn (potato and eggplant) and/or winter (cabbage and dark green leafy vegetables). Various forms of bean curd plus peanuts were the major contributors to legume intake, with their peak seasons of intake occurring primarily in the autumn and/or winter. Pork was the major source of animal protein and rice was the cereal staple over time. The miners drank less green tea but drank more alcohol over time.

Increases in fruit intake $\left(\mathrm{g} \mathrm{day}^{-1}\right)$ might be due to a greater availability of fruits in the market and due to salary increments over time. Local farms began cultivating a greater variety of fruit trees and more produce was brought to the market place in 1995/96 than in 1992/93. For example, mandarin oranges, tangerines and apples were more available in 1995/96 than in 1992/93. Cheaper fruits like plums and pomegranates were eaten less frequently in 1995/96 due to an increase of almost $220 \%$ in salary over time. For the same reasons, 
Table 5 Percentage of individuals who were correctly cross-classified into their quartile of the mean daily frequency of intake based on the DVSs and FFQs: joint classification over time

\begin{tabular}{|c|c|c|c|c|c|c|}
\hline Food & $\begin{array}{c}\% \text { in highest } \\
\text { quartile, } \\
1992\end{array}$ & $\begin{array}{c}\% \text { in lowest } \\
\text { quartile, } \\
1992\end{array}$ & $\begin{array}{c}\% \text { in highest } \\
\text { quartile, } \\
1993\end{array}$ & $\begin{array}{c}\% \text { in lowest } \\
\text { quartile, } \\
1993\end{array}$ & $\begin{array}{c}\% \text { in highest } \\
\text { quartile, } \\
1995\end{array}$ & $\begin{array}{c}\% \text { in lowest } \\
\text { quartile, } \\
1995\end{array}$ \\
\hline \multicolumn{7}{|l|}{ Fruits } \\
\hline Bananas & 64 & $x$ & 38 & $x$ & 23 & $x$ \\
\hline Apples & 33 & $\mathrm{x}$ & 22 & $\mathrm{x}$ & 40 & $\mathrm{x}$ \\
\hline Watermelon & 33 & $\mathrm{x}$ & 25 & $\mathrm{x}$ & 68 & $\mathrm{x}$ \\
\hline Peaches & 40 & $\mathrm{x}$ & 44 & $\mathrm{x}$ & 60 & $\mathrm{x}$ \\
\hline Pears & 50 & $\mathrm{x}$ & 44 & $\mathrm{x}$ & 50 & $\mathrm{x}$ \\
\hline Oranges/tangerines & 40 & $\mathrm{x}$ & 22 & $\mathrm{x}$ & 14 & $x$ \\
\hline \multicolumn{7}{|l|}{ Vegetables } \\
\hline Potato & 32 & 43 & 28 & 25 & 35 & 21 \\
\hline Roots & 11 & 19 & 30 & 40 & 14 & 18 \\
\hline Scallions/leeks & 33 & 19 & 18 & 19 & $x$ & $\mathrm{x}$ \\
\hline Fresh eggplant & 43 & 17 & 27 & 18 & 4 & 39 \\
\hline Cabbage & 25 & 21 & 28 & 9 & 56 & 53 \\
\hline DGLV & 36 & 23 & 48 & 15 & 31 & 22 \\
\hline \multicolumn{7}{|l|}{ Legumes } \\
\hline Fresh bean curd & 53 & 22 & 62 & 28 & 30 & 22 \\
\hline Preserved bean curd & 30 & $\mathrm{x}$ & 22 & $\mathrm{x}$ & 0 & $\mathrm{x}$ \\
\hline Bean sprouts & 35 & 18 & 43 & 11 & 29 & $x$ \\
\hline Peanuts & 56 & 41 & 65 & 10 & 73 & 33 \\
\hline \multicolumn{7}{|l|}{ Animal protein sources } \\
\hline Pork & 37 & 24 & 26 & 18 & 50 & 41 \\
\hline Eggs & 56 & 35 & 16 & 27 & 16 & 25 \\
\hline Beef & 36 & 36 & 50 & 11 & 21 & 14 \\
\hline Preserved pork & 20 & 33 & 22 & 18 & 25 & 26 \\
\hline Fish & 32 & 33 & 39 & 26 & 19 & 17 \\
\hline Chicken & 52 & $x$ & 58 & $x$ & 24 & 37 \\
\hline \multicolumn{7}{|l|}{ Staples and beverages } \\
\hline Rice & 70 & $x$ & 90 & $x$ & 71 & $x$ \\
\hline Noodles & 54 & 21 & 49 & 42 & 52 & 11 \\
\hline Green tea & 92 & 43 & 97 & 32 & 100 & 43 \\
\hline Liquor & 46 & 57 & 65 & 73 & 76 & 70 \\
\hline
\end{tabular}

$x$, insufficient range in responses to create four distinct quartiles; DGLV, dark green leafy vegetables.

intakes of pork and beef from local farms were on the decline, while imported chicken and fish consumption increased over time.

\section{Reported frequency of intake of foods from food recalls vs. FFQs}

The average frequency of food intake was higher in the food recalls than the FFQs over time, which has been reported in some ${ }^{10,11}$ but not other ${ }^{9,12}$ studies. Fruits, vegetables, meats and legumes might have been eaten more frequently during a food recall week, because only $8-10 \%$ of the population owned a refrigerator for perishable food storage and therefore most miners needed to eat food until none remained. In contrast, foods that do not require refrigeration, such as noodles, rice, preserved bean curd and bananas had similar frequencies of intake in both dietary tools or even higher frequencies in the FFQ than the food recalls. Because food recall weeks excluded holidays, miners reported drinking liquor more frequently in the FFQ than in the 1992/93 food recalls. Similar findings about alcohol intake appeared in two studies ${ }^{11,13}$, but not in other studies ${ }^{8,12,14-16}$.

Another explanation for the differences in the frequency of food intake across the dietary tools might be related to the cultural perception of time. The FFQ focused on the annual frequency of intake of a food with a seasonal adjustment. The respondent might, however, have had difficulty estimating his frequency of food intake over the past year, especially taking into account different seasonal patterns of intake of many foods. In contrast, the interviewer asked the respondent to recall his intake over the past 24 hours in the food recalls, with daily review of the recall by a supervisor. Thus, the potential lack of cultural awareness of the past year as a unit of time versus the orientation toward time in relation to meals over the past 24 hours might have contributed to the differences in the frequency of food intake across the tools.

Our analyses were restricted to consumers of foods (Appendix 1). Fruits were the only food group with an appreciable difference in their frequency of intake 
across the dietary tools and a smaller percentage of consumers during food recall weeks versus the FFQ. All other food groups had a similar percentage of consumers across dietary tools, and therefore the higher frequency of vegetable, legume and animal protein intake in the food recalls than the FFQ would not appear to be biased. In an analysis of consumers and non-consumers of fruits, the frequency of individual fruit intake was slightly lower in the food recalls than the FFQ.

\section{Correlation between dietary tools}

Similar to earlier research, the deattenuated correlations were higher than the crude ones, but the range in correlations in this study was lower than previously reported $^{8,10,15-17}$. Potential reasons for our low correlations include: season of and variation in dietary tool administration; few consumers of specific foods; and problems in food recall. Whereas the FFQ was administered every spring and summer, peak vegetable and legume consumption occurred primarily in the autumn and/or winter. These seasonal differences in vegetable and legume intake in contrast with the dates of the FFQ administration might have led respondents to systematically underestimate the frequency of food intake in both food groups in the FFQ, thereby producing low correlations.

Another explanation for the low correlation for legumes and vegetables might be due to differences in dietary tool administration. Whereas the FFQ focused on individual food intake, the food recalls focused on intake of single or multiple ingredient dishes. Because most vegetables and legumes were consumed in mixed dishes, the identification of a mixed dish followed by the multiple food components in each dish could have facilitated reporting these foods in food recalls.

Few miners reported eating fruit in the food recalls (Appendix 1), and therefore the small sample size might have been insufficient to calculate correlations of fruit intake across dietary tools. Only bananas were eaten by a large number throughout the year, and the correlation for bananas was consistently the highest of all the fruits. Staples such as grains and beverages, that were eaten with the highest frequency, had the highest correlation, similar to the findings of others ${ }^{12}$. Finally, correlations that were weighted to adjust for demographic differences between the DVS sample and the baseline cohort were not appreciably different from the crude ones (data not shown).

Because correlations were based on consumers in the DVS, we examined whether miners who did not report consuming a food during the food recalls, but who reported its intake on the FFQ, differed from those who reported consuming the food in both dietary tools. In a subsample of foods, non-consumers during the food recall weeks, who reported intake on the FFQ, had a similar or slightly lower average frequency of intake of each food on the FFQ compared to those who reported consuming the food in both dietary tools. This finding has implications for the use of the FFQ in dietdisease relationships.

\section{Joint classification of individuals in the DVS and $F F Q$}

The percentage of individuals with exact agreement in the extreme quartiles had a larger range than prior dietary validation research has shown ${ }^{11,13-15}$. Possible reasons for the large range include: differences in the administration of, and seasons of, dietary tool collection; a higher frequency of intake during food recall weeks than over the year; and a limited distribution of the frequency of intake of particular foods. Whereas the first two reasons have been addressed in earlier parts of the discussion, ranking was dependent upon a range in the distribution of the frequency of intake of a food. However, for foods such as rice and noodles, the frequency of intake of each food was dichotomous in both dietary tools, and therefore a miner had a $50: 50$ chance of accurately recalling his intake. Other foods had such a limited distribution that an ' $\mathrm{x}$ ' indicated an inability for the data to be categorized into quartiles.

Food recall data collection has limitations, including an inability to measure foods during preparation and/ or consumption; and when data collection occurs over consecutive days, the potential that the respondent has limited his dietary intake to facilitate recall ${ }^{18,19}$. Also, most miners did not prepare or cook their meals, and therefore individual ingredients in mixed dishes might be difficult to recall in both dietary tools ${ }^{16}$. Although 28 days of food recalls over four seasons of the year are considered a relatively high number of recalls to address intra- and interindividual variability in intake, the deattenuated correlation for watermelon was above one because of its high intra- to interindividual variability as observed in another study ${ }^{12}$. Moreover this culture had a very homogenous diet during the food recall weeks because of market availability of food and lack of refrigeration to store food. Therefore, in certain respects, 1 week of food recalls per season might not have been the optimal design but was the most logistically feasible one, because the population was geographically scattered over a large area.

\section{Conclusion}

Changes in food intake over time have implications for modelling the diet-lung cancer analysis. Based on experimental and epidemiological research, many foods or food components have been shown to play a role in lung carcinogenesis ${ }^{20-22}$. The traditional aetiological 
model has examined the association between baseline dietary intake and risk of lung cancer. However, our findings suggest that, in populations undergoing dramatic change, diet might be considered a timedependent variable in the analysis.

In summary, a culture-specific FFQ was created for use in a longitudinal cohort study of tin miners at high risk for lung cancer. Based on 28 days of food recalls during two DVSs, the tin miners experienced changes in dietary intake and in seasonal patterns of intake over time. A seasonally adjusted response to food questions in the FFQ was calculated for comparable assessment of the correlation between foods in the dietary tools. Both correlations and the percentage of miners with exact agreement in the extreme quartiles of both tools tended to be higher for staples and beverages than for fruits, vegetables, animal protein sources and legumes. Results of the two DVSs demonstrated relatively poor correlations for items in the FFQ in several food groups. Several steps are being taken to assess diet validation, including a translation of cafeteria menus in a subset of 1992/93 DVS miners who reported eating meals at the cafeteria during food recall weeks; and an examination of diet-biochemical relationships on a seasonspecific basis and then over the year to determine whether blood and urine levels of antioxidants are correlated with dietary intake in both tools. It is recognized that problems in conducting dietary validation research in cultures with mixed dishes, dramatic economic change and cultural perceptions about time that might be at variance with the administration of a dietary FFQ will continue to challenge the field.

\section{References}

1 Lee MM, Lee F, Ladenla SW, Nude R. A semiquantitative history questionnaire for Chinese Americans. Ann. Epidemiol. 1994; 4: 188-97.

2 Forman MR, Hundt GL, Berendes HW, et al. Undernutrition among Bedouin Arab children: a follow-up of the Bedouin Infant Feeding Study. Am. J. Clin. Nutr. 1995; 61: 495-500.

3 Li L, Lu F, Zhang S, et al. Analysis of cancer mortality and distribution in China 1990-1992: an epidemiologic study. Chin. J. Oncol. 1996; 18(6): 404-5.

4 Qiao YL, Taylor PR, Yao SX, et al. Risk factors and early detection of lung cancer in a cohort of Chinese tin miners. Ann. Epidemiol. 1997; 7: 533-41.

5 Forman MR, Yao SX, Graubard BI, et al. The effect of dietary intake of fruits and vegetables on the odds ratio of lung cancer among Yunnan tin miners. Int.J. Epidemiol. 1992; 21 437-41.

6 Swanson CA, Mao BL, Li JY, et al. Dietary determinants of lung-cancer risk: results from a case-control study in Yunnan Province, China. Int. J. Cancer 1992; 50: 86-89.

7 Rosner B, Willett WC. Interval estimates for correlation coefficients corrected for within-person variation. Implications for study design and hypothesis testing. Am. J Epidemiol. 1988; 127: 377-86.

8 Willett WC, Sampson L, Stampfer MJ, et al. Reproducibility and validity of a semiquantitative food frequency questionnaire. Am. J. Epidemiol. 1985; 122: 51-65.

9 Salvini S, Hunter DJ, Sampson L, et al. Food-based validation of a dietary questionnaire: the effects of week-to-week variation in food consumption. Int. J. Epidemiol. 1989; 18: 858-67.

10 Goldbohm RA, van den Brandt PA, Brants HAM, et al. Validation of a dietary questionnaire used in a large-scale prospective cohort study of diet and cancer. Eur. J. Clin. Nutr. 1994; 48: 253-65.

11 Rimm EB, Giovannucci EL, Stampfer MJ, et al. Reproducibility and validity of an expanded self-administered semiquantitative food frequency questionnaire among male health professionals. Am. J. Epidemiol. 1992; 135: 1114-26.

12 Feskanich D, Rimm RE, Giovannuci EL, et al. Reproducibility and validity of food intake measurements from a semiquantitative food frequency questionnaire. J. Am. Diet. Assoc. 1993; 93: 790-6.

13 Pisani P, Faggiano F, Krogh V, et al. Relative validity and reproducibility of a food frequency dietary questionnaire for use in the Italian EPIC centres. Int. J. Epidemiol. 1997; 26 (Suppl.): S152-60.

14 Ocke MC, Bueno-de-Mesquita HB, Goddijn HE, et al. The Dutch EPIC food frequency questionnaire. I. Description of the questionnaire, and relative validity and reproducibility for food groups. Int. J. Epidemiol. 1997; 26 (Suppl. 1): S3748.

15 EPIC Group of Spain. Relative validity and reproducibility of a diet history questionnaire in Spain. I. Foods. Int. J. Epidemiol. 1997; 26 (Suppl. 1): S91-9.

16 Date C, Yamaguchi M, Tanaka H. Development of a food frequency questionnaire in Japan. J. Epidemiol. 1996; 6: S131-5.

17 Van Liere M, Lucas F, Clavel F, et al. Relative validity and reproducibility of a French dietary history questionnaire. Int. J. Epidemiol. 1997; 26 (Suppl. 1): S128-36.

18 Bohlscheid-Thomas S, Hoting I, Boeing H, Wahrendorf J. Reproducibility and relative validity of food group intake in a food frequency questionnaire developed for the German part of the EPIC project. Int.J. Epidemiol. 1997; 26 (Suppl. 1): S59-70.

19 Thompson FE, Byers T. Dietary assessment resource manual. J. Nutr. 1994; 124: S245-317.

20 Ziegler RG. A review of epidemiologic evidence that carotenoids reduce the risk of cancer. J. Nutr. 1989; 119: 116-22.

21 Sporn MB, Newton DL. Chemoprevention of cancer with retenoids. Fed. Proceed. 1979; 38: 2528-34.

22 Steinmetz KA, Potter JD. Vegetables, fruit, and cancer. I: Epidemiology. Cancer Causes Control 1991; 2: 325-57. 
Appendix 1: percentage of consumers of individual foods by dietary tool

\begin{tabular}{|c|c|c|c|c|c|}
\hline Food & $1992 / 93$ DVS $(n=141)$ & $1992 \mathrm{FFQ}$ & $1993 \mathrm{FFQ}$ & $1995 / 96$ DVS $(n=113)$ & $1995 \mathrm{FFQ}$ \\
\hline \multicolumn{6}{|l|}{ Fruits } \\
\hline Bananas & 57 & 95 & 85 & 46 & 96 \\
\hline Apples & 38 & 87 & 81 & 39 & 96 \\
\hline Watermelon & 23 & 86 & 81 & 45 & 97 \\
\hline Peaches & 23 & 86 & 80 & 27 & 94 \\
\hline Pears & 25 & 91 & 84 & 29 & 98 \\
\hline Oranges/tangerines & 14 & 97 & 86 & 39 & 40 \\
\hline \multicolumn{6}{|l|}{ Vegetables } \\
\hline Potato & 97 & 97 & 90 & 97 & 100 \\
\hline Roots & 100 & 98 & 86 & 89 & 100 \\
\hline Scallions/leeks & 100 & 99 & 91 & 100 & 100 \\
\hline Fresh eggplant & 99 & 89 & 80 & 83 & 94 \\
\hline Cabbage & 100 & 91 & 82 & 99 & 100 \\
\hline DGLV & 90 & 98 & 88 & 95 & 100 \\
\hline \multicolumn{6}{|l|}{ Legumes } \\
\hline Fresh bean curd & 100 & 97 & 88 & 98 & 99 \\
\hline Preserved bean curd & 40 & 60 & 55 & 58 & 73 \\
\hline Bean sprouts & 82 & 89 & 81 & 76 & 98 \\
\hline Peanuts & 93 & 97 & 87 & 91 & 100 \\
\hline \multicolumn{6}{|l|}{ Animal protein sources } \\
\hline Pork & 100 & 100 & 91 & 99 & 99 \\
\hline Eggs & 99 & 98 & 87 & 94 & 92 \\
\hline Beef & 77 & 70 & 61 & 57 & 83 \\
\hline Preserved pork & 87 & 80 & 73 & 76 & 96 \\
\hline Fish & 70 & 94 & 82 & 77 & 94 \\
\hline Chicken & 72 & 99 & 90 & 83 & 99 \\
\hline \multicolumn{6}{|l|}{ Staples and beverages } \\
\hline Rice & 100 & 100 & 91 & 100 & 100 \\
\hline Noodles & 99 & 98 & 85 & 99 & 98 \\
\hline Green tea & 100 & 87 & 79 & 94 & 92 \\
\hline Liquor & 82 & 78 & 62 & 80 & 76 \\
\hline
\end{tabular}

DGLV, dark green leafy vegetables. 